\title{
Nitric Oxide and Superoxide Contribute to Motor Neuron Apoptosis Induced by Trophic Factor Deprivation
}

\author{
Alvaro G. Estévez, ${ }^{1,4}$ Nathan Spear, ${ }^{1,4}$ S. Machelle Manuel, ${ }^{1,4}$ Rafael Radi, ${ }^{5}$ Christopher E. Henderson, ${ }^{7}$ \\ Luis Barbeito, ${ }^{6,8}$ and Joseph S. Beckman ${ }^{1,2,3,4}$ \\ Departments of ${ }^{1}$ Anesthesiology, ${ }^{2}$ Biochemistry and Molecular Genetics, ${ }^{3}$ Neurobiology, and 4 The UAB Center for Free \\ Radical Biology, The University of Alabama at Birmingham, Birmingham, Alabama 35233, ${ }^{5}$ Departamento de Bioquímica, \\ Facultad de Medicina, and 'Sección Neurociencias, Facultad de Ciencias, Universidad de la República, Montevideo, \\ Uruguay 7Institut National de la Santé et de la Recherche Médicale (INSERM) Unité 382, Developmental Biology Institute \\ of Marseille (IBDM) (Centre National de la Recherche Scientifique-INSERM-Université de la Mediterranée), 13288 \\ Marseille Cedex 09, France, and División Neurobiología Celular y Molecular, Instituto Clemente Estable, 11600 \\ Montevideo, Uruguay
}

Primary cultures of rat embryonic motor neurons deprived of brain-derived neurotrophic factor (BDNF) induce neuronal nitric oxide synthase (NOS) within $18 \mathrm{hr}$. Subsequently, $>60 \%$ of the neurons undergo apoptosis between 18 and $24 \mathrm{hr}$ after plating. Nitro-L-arginine and nitro-L-arginine methyl ester (L-NAME) prevented motor neuron death induced by trophic factor deprivation. Exogenous generation of nitric oxide at concentrations lower than 100 nM overcame the protection by L-NAME. Manganese tetrakis (4-benzoyl acid) porphyrin, a cell-permeant superoxide scavenger, also prevented nitric oxide-dependent motor neuron death. Motor neurons cultured without trophic support rapidly became immunoreactive for nitrotyrosine when compared with motor neurons incubated with BDNF, L-NAME, or manganese TBAP. Our results suggest that peroxynitrite, a strong oxidant formed by the reaction of $\mathrm{NO}$ and superoxide, plays an important role in the induction of apoptosis in motor neurons deprived of trophic factors and that BDNF supports motor neuron survival in part by preventing neuronal NOS expression.

Key words: motor neuron; nitric oxide synthase; superoxide; peroxynitrite; nitrotyrosine; apoptosis; nitric oxide
The production of nitric oxide (NO) has been implicated in neuronal injury after ischemia, trauma, and numerous neurodegenerative disorders, including amyotrophic lateral sclerosis (ALS) (Huang et al., 1994; Beckman et al., 1996). Oxidative stress also is involved in the induction of neuron death in neurodegeneration (Coyle and Puttfarcken, 1993). Excessive stimulation of glutamate receptors may mediate neuron death by the production of both nitric oxide (Dawson et al., 1991, 1996) and superoxide (Lafon-Cazal et al., 1993a,b; Culcasi et al., 1994). Nitric oxide and superoxide combine by a diff usion-limited reaction to form the much stronger and more toxic oxidant peroxynitrite $\left(\mathrm{ONOO}^{-}\right)$(Beckman, 1996a). Peroxynitrite stimulates apoptosis of PC12 cells (Estévez et al., 1995; Troy et al., 1996; Spear

\footnotetext{
Received Aug. 13, 1997; revised Oct. 2, 1997; accepted Nov. 7, 1997.

This work was supported by grants from National Institutes of Health and American Amyotrophic Lateral Sclerosis Association (to J.S.B.), Comisión Sectorial de Investigación Científica Universidad de la República (to A.G.E.), and Proyecto Banco Interamericano de Desarrollo-Consejo Nacional de Investigaciones Científicas y Técnicas (to L.B.). N.S. is supported in part by the Basic Mechanisms in Lung Disease Training Fellowship HL07533 from National Institutes of Health. We thank Drs. S. H. Snyder and A. M. Snowman from Johns Hopkins University for the generous gift of neuronal NOS cDNA; Genentech, Incorporated for neurotrophin4/5; R. W. Scott and J. D. Hirsch from Cephalon, Incorporated for BDNF; Dr. B. Mayer for neuronal NOS antibodies and blocking peptide; S. Matalon for the use of the fluorescence microscope; Drs. K. Conger, Y. Zhuang, and Y. Z. Ye for helpf ul suggestions and assistance; and Drs. J. Crow, J. P. Eiserich, and J. A. Thompson for helpful comments on this manuscript.

Correspondence should be addressed to Dr. Alvaro G. Estévez, Department of Anesthesiology, Research Division, University of Alabama at Birmingham, 1900 University Boulevard, THT 958, Birmingham, AL 35233.

Dr. Manuel's present address: School of Pharmacy, Texas Tech University Health Sciences Center, Amarillo, TX 79106.

Copyright (C) 1998 Society for Neuroscience $0270-6474 / 98 / 180923-09 \$ 05.00 / 0$
}

et al., 1997) and cortical neurons in culture (Bonfoco et al., 1995). Peroxynitrite is a substrate for superoxide dismutase (SOD), which catalyzes the nitration of tyrosines on other proteins (Ischiropoulos et al., 1992). Indeed, we have suggested previously that SOD-catalyzed tyrosine nitration may be involved in the pathogenesis of ALS (Beckman et al., 1993). Nitrotyrosine immunoreactivity is found in Alzheimer's disease (Good et al., 1996; Smith et al., 1997), ALS (Abe et al., 1995; Chou et al., 1996a,b), and animal models of Parkinson's disease (Hantraye et al., 1996; Przedborski et al., 1996; Schulz et al., 1996).

Chronic treatment with trophic factors prevents programmed cell death of motor neurons during chicken spinal cord development (Oppenheim et al., 1992, 1995; Neff et al., 1993) and motor neuron loss after axonal injury in mammals (Sendtner et al., 1992; Yan et al., 1992, 1993; Hughes et al., 1993; Henderson et al., 1994; Li et al., 1995; Schmalbruch and Rosenthal, 1995; Pennica et al., 1996). Trophic factor deprivation leads to degeneration of cultured motor neurons by apoptosis (Milligan et al., 1995; Pennica et al., 1996), and a variety of neurotrophins, cytokines, and other factors can rescue motor neurons in culture from apoptosis (Arakawa et al., 1990; Henderson et al., 1993, 1994; Hughes et al., 1993; Gouin et al., 1996; Pennica et al., 1996). However, the mechanisms leading to apoptosis in motor neurons subjected to trophic factor deprivation remain elusive. Recent evidence suggests that the production of nitric oxide may be involved in the process of spinal motor neuron death stimulated by ventral root avulsion. After the injury, motor neurons induce nitric oxide synthase (NOS), and the subsequent cell death is prevented mainly by chronic administration of NOS inhibitors (Wu, 1993; 
Wu and Li, 1993). However, the mechanism of NO-mediated toxicity is still unknown. We therefore investigated whether endogenous production of NO contributed to apoptosis in high purity cultures of fetal rat motor neurons deprived of trophic support. We found that trophic factor deprivation increased both motor neuron expression of neuronal NOS and nitrotyrosine immunoreactivity. NOS inhibitors and a membrane-permeant SOD mimetic mainly prevented motor neuron death and blocked the increase in nitrotyrosine immunoreactivity. These results support a peroxynitrite-dependent induction of motor neuron apoptosis.

\section{MATERIALS AND METHODS}

Materials. Monoclonal antibodies to Islet-1/2 were isolated from media from 4D5 hybridoma cells obtained from the Developmental Studies Hybridoma Bank (Iowa City, IA) (Ericson et al., 1992; Tsuchida et al., 1994). Polyclonal antibodies to neuronal NOS were obtained from Transduction Laboratories (Lexington, KY) and the generous gift of Dr. B. Mayer (Graz, Austria). Affinity-purified anti-mouse IgG was obtained from Cappel (Durham, NC). Affinity-purified biotinylated goat antimouse and anti-rabbit antibodies and FITC- and Texas Red-conjugated streptavidin were obtained from Life Technologies (Grand Island, NY). Cy3-conjugated goat anti-mouse and anti-rabbit were from Jackson Laboratories (West Grove, PA). Mounting medium was SlowFade-Light antifade kit from Molecular Probes (Eugene, OR). Recombinant mouse BDNF was a generous gift from R. W. Scott and J. D. Hirsch (Cephalon,

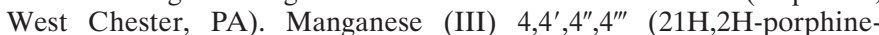
5,10,15,20-tetrayl)tetrakis (benzoic acid), better known as manganese TBAP, was purchased from Calbiochem (La Jolla, CA). Culture media, serum, insulin, and antibiotics were from Life Technologies. All other reagents used were obtained from Sigma (St. Louis, MO).

Motor neuron culture. Motor neurons were prepared from embryonic day 15 (E15) rat embryo spinal cord by a combination of metrizamide gradient centrifugation and immunopanning with the monoclonal antibody IgG192 (Chandler et al., 1984) against the p75 low-affinity neurotrophin receptor, as previously described (Henderson et al., 1995). Briefly, ventral spinal cords were dissected in PBS, treated with trypsin for $15 \mathrm{~min}$ at $37^{\circ} \mathrm{C}$, and dissociated by gentle trituration in $0.1 \%$ bovine serum albumin (BSA) and $0.1 \mathrm{mg} / \mathrm{ml}$ DNase I in basal culture medium (L15 medium supplemented with $0.63 \mathrm{mg} / \mathrm{ml}$ sodium bicarbonate, 5 $\mu \mathrm{g} / \mathrm{ml}$ insulin, $0.1 \mathrm{~mm}$ putrescine, $0.1 \mathrm{mg} / \mathrm{ml}$ conalbumin, $30 \mathrm{~nm}$ sodium selenite, $20 \mathrm{~nm}$ progesterone, $20 \mathrm{~mm}$ glucose, $100 \mathrm{IU} / \mathrm{ml}$ penicillin, 100 $\mu \mathrm{g} / \mathrm{ml}$ streptomycin, and $2 \%$ horse serum). The single-cell suspension was centrifuged on a $6.5 \%$ metrizamide cushion for $15 \mathrm{~min}$ at $500 \times \mathrm{g}$. Motor neurons were removed from the interface. After dilution with basal medium, cells were resuspended in L15 medium and incubated for $30 \mathrm{~min}$ at room temperature in a bacteriological Petri dish previously coated with anti-mouse IgG and MC192 hybridoma supernatant. Nonadherent cells were removed by nine washes with L15 medium, and motor neurons were eluted by gentle agitation with MC192 hybridoma supernatant. Motor neurons were plated at a density of $200 \mathrm{cells} \cdot \mathrm{cm}^{-2}$ on $35 \mathrm{~mm}$ dishes or at a density of $10^{3}$ cells $\mathrm{cm}^{-2}$ on glass coverslips precoated with polyornithine-laminin in basal culture medium. Cultures were maintained at $37^{\circ} \mathrm{C}$ in an atmosphere $5 \% \mathrm{CO}_{2} / 95 \%$ humidified air.

Determination of $m R N A$ expression. Total RNA from 50,000 motor neurons plated on $60 \mathrm{~mm}$ dishes was isolated with Trizol (Life Technologies), reverse-transcribed with an RT-PCR Kit (Stratagene, La Jolla, $\mathrm{CA})$, and amplified with the GeneAmp PCR Reagent Kit (Perkin-Elmer, Emeryville, CA) $\left(1\right.$ cycle at $91^{\circ} \mathrm{C}$ for $5 \mathrm{~min}$ and $54^{\circ} \mathrm{C}$ for $5 \mathrm{~min}$, followed by 30 cycles of $91^{\circ} \mathrm{C}$ for $1 \mathrm{~min}, 54^{\circ} \mathrm{C}$ for $1 \mathrm{~min}, 72^{\circ} \mathrm{C}$ for $2 \mathrm{~min}$, and a final cycle of $72^{\circ} \mathrm{C}$ for $10 \mathrm{~min}$ ). Sense and antisense primers for neuronal NOS were 5'-GAATACCAGCCTGATCCATGGAA and 5'-TCCTCCAGG AGGGTGTCCACCGCATG-3' (Shaul et al., 1995); for glyceraldehyde3-phosphate dehydrogenase (GAPDH) the primers were 5'-ATTCTAC CCACGGCAAGTTCAATGG and 5'-AGGGGCGGAGATGATGA CCC-3'. GAPDH primers were used to normalize RNA levels. The products of the reaction were separated by electrophoresis in a $2 \%$ agarose gel and visualized in a UV transilluminator after staining with ethidium bromide. Gels were digitized, and the intensity of the bands was quantified by using National Institutes of Health Image version 1.60.

Immunofluorescence. Cultures were fixed for 15 min with $4 \%$ paraformaldehyde $/ 0.1 \%$ glutaraldehyde in PBS on ice. The cells were rinsed successively with PBS $(3 \times)$, permeabilized with $0.1 \%$ Triton X-100 for
15 min, blocked for $1 \mathrm{hr}$ with $10 \%$ goat serum plus $2 \%$ BSA in PBS, incubated with the primary antibody overnight at $4^{\circ} \mathrm{C}$, rinsed with PBS (three times), incubated with $\mathrm{Cy} 3$ - or biotin-conjugated secondary antibody for $30 \mathrm{~min}$ at room temperature, rinsed with PBS (three times), incubated with FITC- or Texas Red-conjugated streptavidin, rinsed with PBS (three times), fixed with $4 \%$ paraformaldehyde, rinsed with PBS (three times), and after a final rinse with distilled water, mounted in SlowFade-Light antifade kit. Primary antibodies used were the supernatant from 4D5 hybridoma against Islet-1/2 (1:100), IgG 192 to p75 neurotrophin receptor $(5 \mu \mathrm{g} / \mathrm{ml})$, and affinity-purified rabbit polyclonal antibodies to nitrotyrosine (1:500; Beckman et al., 1994) and for the neuronal NOS (1:100). Controls included omission of primary antibody or permeabilization of the cells for neuronal NOS and Islet-1/2. Immunoreactivity with the neuronal NOS antibody was abolished by preincubation with N-terminal neuronal NOS peptide, as described by Herdergen et al. (1993). Nitrotyrosine staining was blocked by preincubation of the primary antibody $(2 \mu \mathrm{g} / \mathrm{ml})$ with either $5 \mathrm{~mm}$ nitrotyrosine or $100 \mu \mathrm{M}$ alanyl-3-nitrotyrosyl-glycine (Ye et al., 1996). Terminal deoxynucleotidyl transferase-mediated dUTP-biotin nick end labeling (TUNEL) staining used the Apoptosis Detection System from Promega (Madison, WI) according to the manufacturer's instructions.

Quantitative microscopy. Nitrotyrosine immunofluorescence was quantified by randomly selecting cells under interference contrast and then digitizing FITC-fluorescent images. Differential interference contrast and epifluorescence microscopy were performed with an inverted Sedival (Jena) microscope. Images were obtained and analyzed with a Series 200 cooled charge-coupled device camera system (Photometrics, Tucson, AZ) configured for a Macintosh IIci computer that used IPLab Spectrum 2.5.5 software (Signal Analytics, Vienna, VA). A $60 \times$ planachromat objective was used for all images. Illumination for epifluorescence was achieved with a $100 \mathrm{~W}$ mercury arc lamp. Standard filters (485-520 nm excitation filter; 520-560 emission filter) were used for visualizing FITC labeling for nitrotyrosine. Controls were performed by incubating the first antibody $(2 \mu \mathrm{g} / \mathrm{ml})$ in the presence of a $100 \mu \mathrm{M}$ nitrotyrosinecontaining peptide, $5 \mathrm{~mm}$ free nitrotyrosine, or by omission of the primary antibody. None of the controls exhibited significant staining. At least 15 images were collected from each slide. Slides from five independent experiments were digitized into pixels of $0.21 \mu \mathrm{m}^{2}$. Cellular structures in each image were outlined manually with digital imaging techniques. The intensity value of each pixel within the outline area was measured, and a mean intensity was calculated. Fluorescence intensity in areas not covered by cellular structures of each image was measured in a manner identical to standardized conditions. Specific nitrotyrosine content was obtained by subtracting the fluorescence found in the presence of $100 \mu \mathrm{M}$ alanyl-3-nitrotyrosyl-glycine, which blocks specific nitrotyrosine antibody binding, from the fluorescence obtained without the peptide.

Determination of motor neuron survival. Motor neuron survival was quantified 24 and $72 \mathrm{hr}$ after plating by counting all neurons with neurites longer than 4 soma diameters in a $1 \mathrm{~cm}^{2}$ field in the center of the dish, as previously described (Henderson et al., 1993; Pennica et al., 1996). Motor neurons considered viable by this method also were stained with the vital dye fluorescein diacetate. To compare the results of different experiments, we took the number of cells attached with neurites $4 \mathrm{hr}$ after plating in the presence of BDNF as $100 \%$ survival that corresponded to $\sim 50-60 \%$ of the cells that were plated initially (Henderson et al., 1993).

\section{RESULTS}

\section{Trophic factor deprivation leads to apoptosis}

Trophic factor-deprived motor neurons attached to the substrate and extended neurites during the first 15-18 hr in culture, as in BDNF-treated cultures, but then the motor neurons became shrunken and round and withdrew their neurites. These cells also showed nuclear condensation and evidence of DNA fragmentation, visualized by the TUNEL method at $24 \mathrm{hr}$ (Fig. 1a,b). More than $60 \%$ of motor neurons in culture underwent apoptosis when they were deprived of trophic support during the first $24 \mathrm{hr}$. Further evidence for motor neuron apoptosis was provided by treating them with the caspase inhibitors Ac-YVAD-CHO and Ac-YAVD-CMK. Both agents significantly reduced motor neuron degeneration 

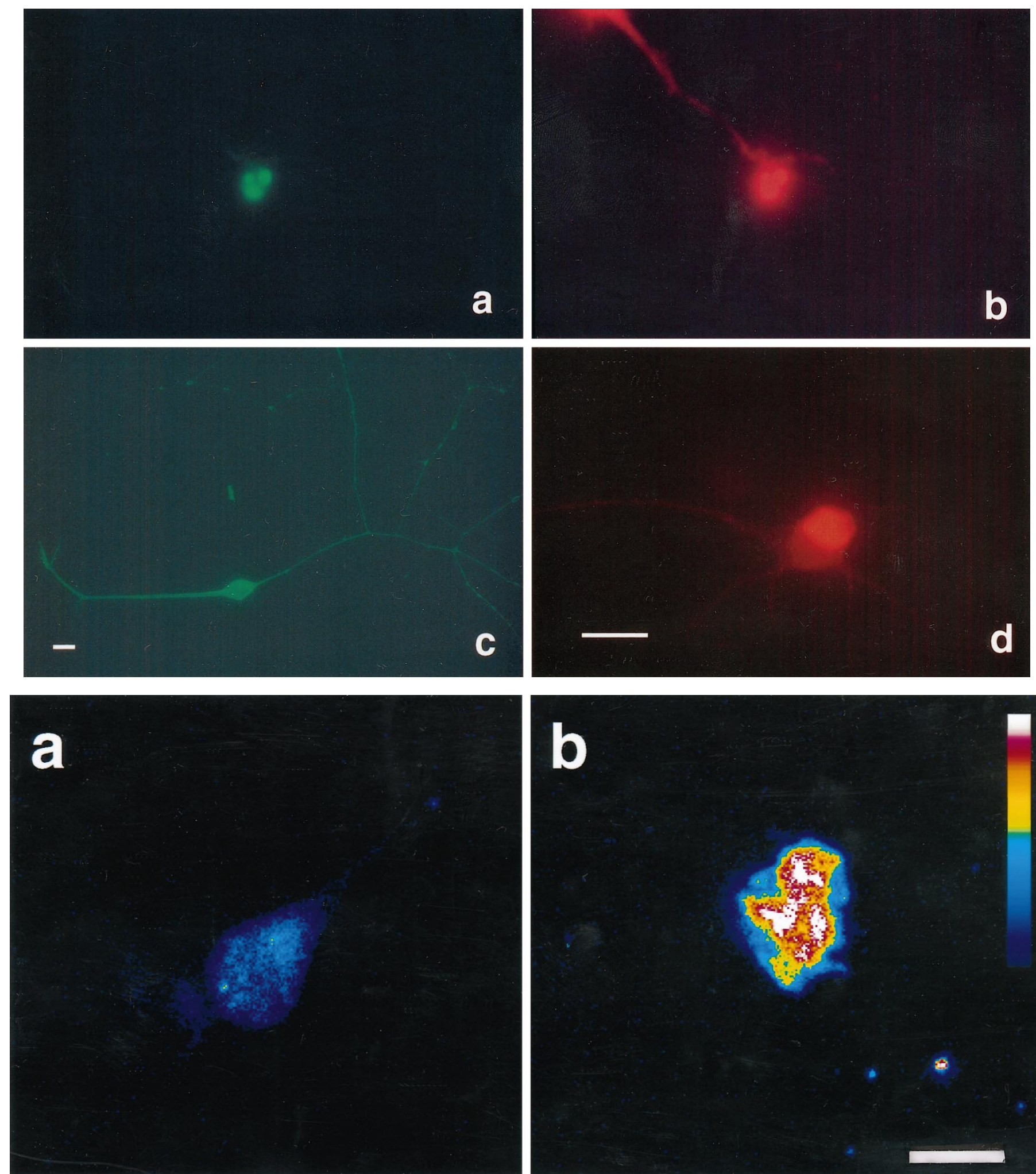

Figure 1. Top. Trophic factor deprivation induced motor neuron apoptosis. $a$, TUNEL staining of the nucleus of an apoptotic motor neuron cultured for $24 \mathrm{hr}$ without trophic factors. $b$, Propidium iodide counterstaining of the same cell shown in $a$. $c$, A nonapoptotic motor neuron cultured with BDNF $(100 \mathrm{pg} / \mathrm{ml})$ for $24 \mathrm{hr}$ showed characteristic long, branched neurites, as shown by immunofluorescence of the p75 neurotrophin receptor. $d$, Immunofluorescence of a BDNF-treated motor neuron for the Islet-1/2 homeoprotein. Nonpermeabilized cells did not show nuclear staining for Islet-1/2; the cytoplasmic staining reflects the binding of the secondary antibody to the IgG192 antibody against p75 remaining from the isolation process. Scale bars, $30 \mu \mathrm{m}$; the scale bar shown in $d$ is the same for $a$ and $b$.

Figure 4. Bottom. Increased neuronal NOS immunoreactivity in trophic factor-deprived motor neurons. Shown are confocal pseudocolor images of motor neurons cultured for $24 \mathrm{hr}(a)$ with BDNF $100 \mathrm{pg} / \mathrm{ml}$ or $(b)$ without trophic support and stained by using antibodies to neuronal NOS. The slight staining in $a$ is attributable to the secondary antibody, because similar immunofluorescence intensity is present in the absence of the first antibody. Scale bar, $10 \mu \mathrm{m}$. 


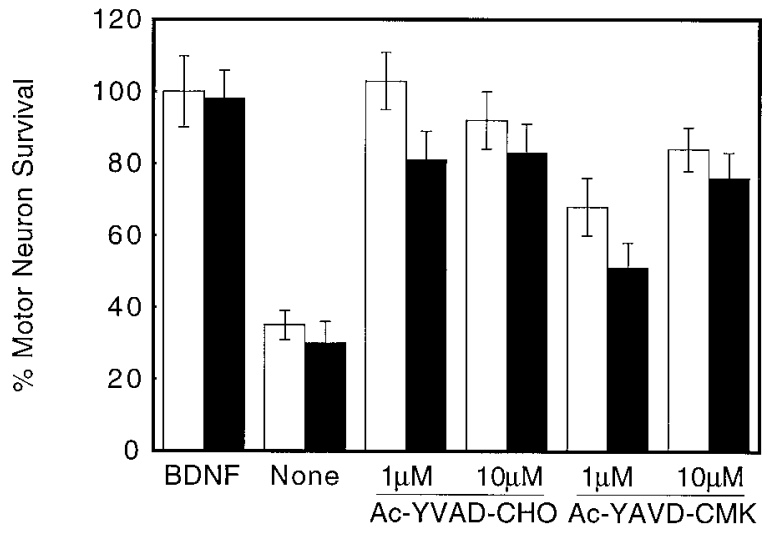

Figure 2. Caspase inhibitors prevented trophic factor-induced motor neuron death. The inhibitors were added immediately after plating and every $24 \mathrm{hr}$ at the indicated concentrations. Motor neuron survival was determined 24 (open bars) and 72 (solid bars) hr later, as described in Materials and Methods. Values are the mean \pm SD of two independent experiments performed in duplicate.

for $24 \mathrm{hr}$ and up to $3 \mathrm{~d}$ (Fig. 2), as previously described for avian motor neurons in culture (Milligan et al., 1995).

Motor neurons cultured in the presence of BDNF or neurotrophin-4/5 (NT4/5) for $24 \mathrm{hr}$ developed long, branched neurites. Over $96 \%$ of the cells were immunoreactive for the motor neuron markers p75 neurotrophin receptor and Islet-1/2 (Fig. 1b,c; Yan and Johnson, 1988; Tsuchida et al., 1994). However, motor neurons in L15 medium survived for a maximum of $72 \mathrm{hr}$ before undergoing apoptosis even in the presence of BDNF or NT4/5 (see Fig. 6).

\section{Trophic factor deprivation induces neuronal NOS}

BDNF-deprived motor neurons expressed neuronal NOS mRNA that was not detected in BDNF-treated cultures (Fig. 3). In contrast, $25 \%$ less mRNA for GAPDH was recovered by RT-PCR from trophic factor-deprived cultures as compared with BDNFtreated cultures. Similarly, trophic factor-deprived motor neurons became immunoreactive for neuronal NOS $24 \mathrm{hr}$ after plating (Fig. 4). Although neuronal NOS immunoreactivity was restricted

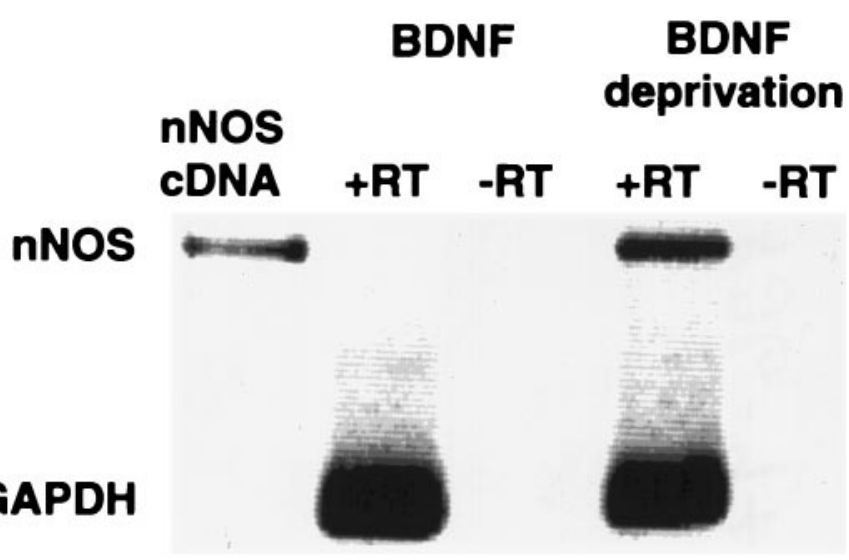

Figure 3. Induction of neuronal nitric oxide synthase gene expression by trophic factor deprivation in cultured motor neurons. Shown is mRNA expression for neuronal NOS in cultured motor neurons by RT-PCR. Total RNA from 50,000 motor neurons was extracted $24 \mathrm{hr}$ after plating. One-half of the RNA was incubated with reverse transcriptase (RT) before PCR $(+R T)$, whereas the other one-half was amplified without RT $(-R T)$. cDNA from neuronal NOS was used as the standard. to specific areas of cytoplasm in some apoptotic cells (data not shown), in later stages of apoptotic degeneration the fluorescence was distributed throughout the cell because of the disorganization of cellular structures and nuclear condensation (Fig. 1b). Neither neuronal NOS mRNA nor immunoreactivity could be detected in BDNF-treated cultures. Identical results were obtained by using two different anti-neuronal NOS polyclonal antibodies. Fluorescence was not present in cultures that were not permeabilized and abolished by preincubation of the primary antibody with the N-terminal peptide of the neuronal NOS (Herdegen et al., 1993, 1994; Meyer et al., 1994).

\section{NOS inhibitors prevent apoptosis}

Inhibition of NOS activity by nitro-L-arginine (L-NA) and nitroL-arginine methyl ester (L-NAME) prevented motor neuron death for up to $3 \mathrm{~d}$ (Fig. $5 A$ ). Both NOS inhibitors prevented motor neuron death in a dose-dependent manner, with an $\mathrm{EC}_{50}$ of 150 and $10 \mu \mathrm{M}$ for L-NA and L-NAME, respectively (Fig. 5B). These concentrations were slightly higher than those reported to be effective in primary cortical cultures, but the motor neuron culture medium contained a fivefold greater concentration of L-arginine. 7-Nitroindazole (7-NI) protected to a lesser extent (Fig. $5 A$ ), but the effect was limited by its low solubility. After $3 \mathrm{~d}$ the survival-promoting effects of BDNF and L-NAME decreased in parallel (Fig. 6). L-NAME protection was abolished by L-arginine but was not affected by $\mathrm{D}$-arginine, and the inactive stereoisomer D-NAME provided no protection (Table 1), indicating that L-NAME protection was attributable to NOS inhibition.

\section{Effects of exogenous NO}

Protection from apoptosis by L-NAME could be overcome by the continuous generation of a physiologically plausible concentration of NO. NO was generated from 2-2'-(hydroxynitrosohydrazino) bis-ethanamine (DETA-NONOate), which has a half-life of $56 \mathrm{hr}$ (Hrabie et al., 1993). At a concentration of $20 \mu \mathrm{M}$, DETANONOate produced a $100 \mathrm{~nm}$ steady-state concentration of NO over $24 \mathrm{hr}$, as measured in complete media (Beckman and Conger, 1995). DETA-NONOate caused L-NAME-treated motor neurons to undergo apoptosis but did not affect the survival of motor neurons cultured with or without BDNF (Table 2), suggesting that the NO itself did not induce apoptosis. The metabolites of the DETA moiety itself did not affect motor neuron viability.

The rate of decay of a bolus addition of NO in basal culture medium in darkness was lower in the presence $\left(t_{1 / 2}=2 \mathrm{~min}\right)$ than in the absence of $\operatorname{SOD}\left(t_{1 / 2}=1 \mathrm{~min}\right)$, suggesting that autoxidation of culture medium produced a flux of superoxide sufficient to inactivate NO. The addition of SOD approximately doubled the amount of NO in the culture medium. Inclusion of SOD in the culture medium potentiated motor neuron death stimulated by DETA-NONOate in the presence of L-NAME (Table 2), but SOD had no effect on survival in the absence of BDNF, demonstrating that SOD increased the toxicity of extracellular NO.

\section{Intracellular superoxide scavenging prevents apoptosis} Extracellular SOD had no effect on motor neuron survival in the absence of BDNF (Table 2). However, a membrane-permeable scavenger of superoxide, manganese TBAP (Faulkner et al., 1994; Szabo et al., 1996), increased survival of BDNF-deprived motor neurons at concentrations higher than $50 \mu \mathrm{M}$ in a dosedependent manner, with an $\mathrm{EC}_{50}$ of $75 \mu \mathrm{M}$ (Fig. 7), suggesting 

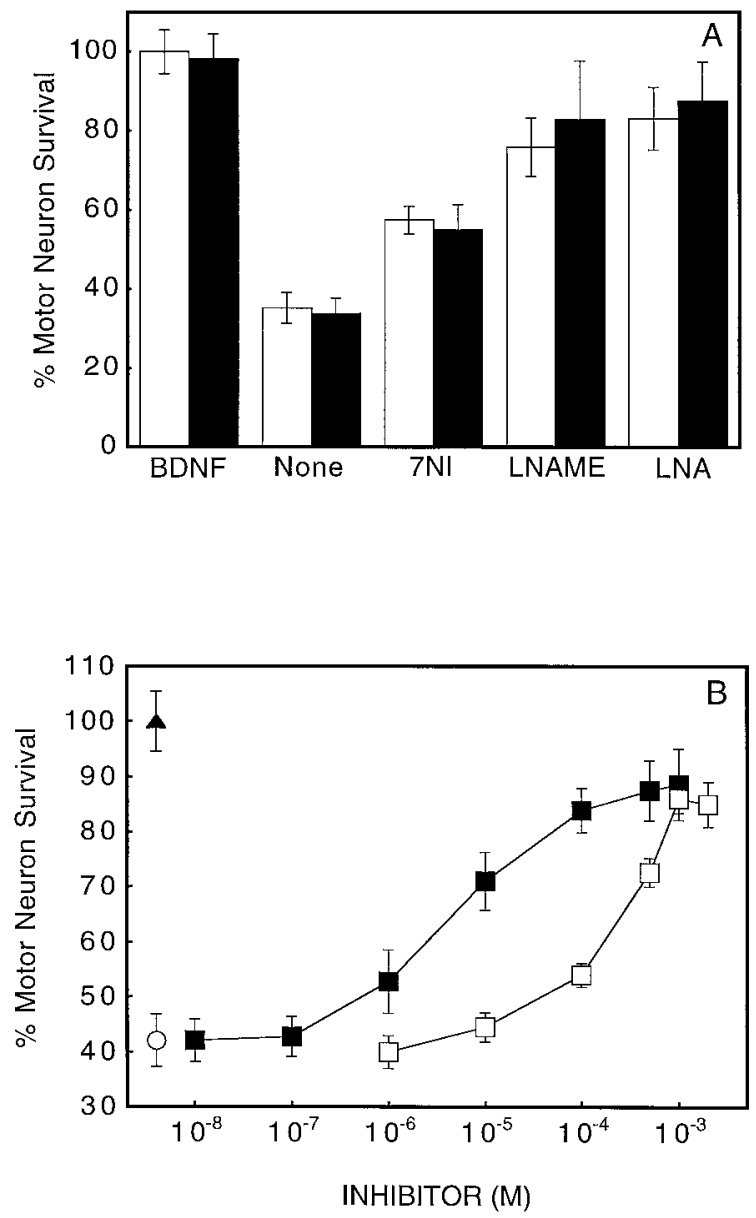

Figure 5. Effect of NOS inhibitors on motor neuron apoptosis induced by trophic factor deprivation. $A$, Prevention of motor neuron death by 5 $\mu \mathrm{M} 7$-nitroindazole $(7 N I), 1 \mathrm{mM}$ nitro-L-arginine methyl ester ( $L-N A M E)$, and $2 \mathrm{~mm}$ nitro-L-arginine (LNA) at $24 \mathrm{hr}$ (open bars) and $72 \mathrm{hr}$ (solid bars) after plating. $B$, L-NAME and L-NA dose-dependent prevention of motor neuron death $24 \mathrm{hr}$ after plating. (A) Neurotrophin- $4 / 5,100 \mathrm{pg} / \mathrm{ml}$; $(\square)$ L-NA; $(\square)$ L-NAME; $(\bigcirc)$ trophic factor deprivation. Values are the mean \pm SD of at least two independent experiments run in duplicate.

that an intracellular increase in superoxide was required to induce cell death.

Low concentrations of manganese TBAP also potentiated the protective effect of L-NAME on motor neuron survival. Individually, $10 \mu \mathrm{M}$ L-NAME and $50 \mu \mathrm{M}$ manganese TBAP increased the survival of trophic factor-deprived motor neurons at $24 \mathrm{hr}$ by only $30 \%$ and $10 \%$, respectively (Fig. 8). In combination, these low concentrations of L-NAME and manganese TBAP increased motor neuron survival by $55 \%$ to provide nearly complete protection (Fig. 8).

\section{Apoptosis is associated with increased nitrotyrosine}

Motor neurons exhibited specific immunoreactivity for nitrotyrosine immediately after the $6 \mathrm{hr}$ isolation procedure (data not shown), which was still evident in all experimental groups $24 \mathrm{hr}$ later (Fig. 9). However, cells cultured without BDNF showed a threefold increase in nitrotyrosine immunofluorescence as compared with motor neurons cultured with BDNF or L-NAME (Fig. 10). Manganese TBAP also blocked nitrotyrosine immunoreactivity in BDNF-deprived neurons. In contrast, exogenous gener-

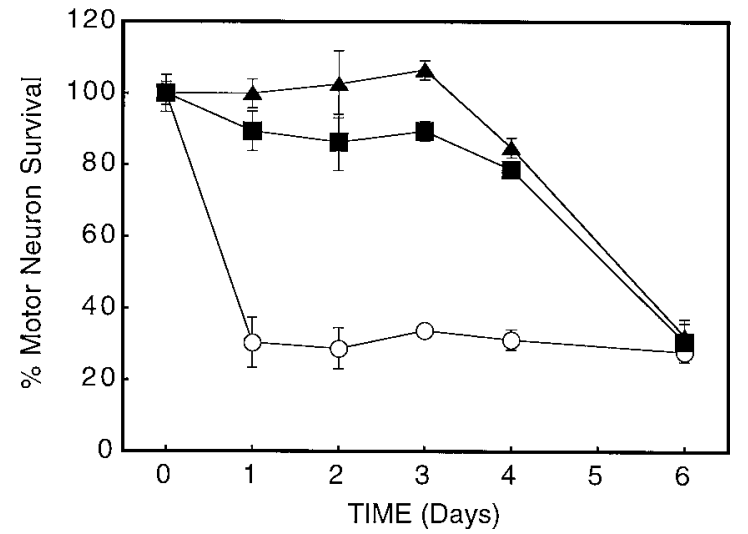

Figure 6. Time course of motor neuron degeneration. Motor neuron survival was determined at the indicated times after plating by counting under phase-contrast microscopy all neurons with neurites longer than 4 soma in diameter in the same $1 \mathrm{~cm}^{2}$ field in the center of the dish. $(\boldsymbol{\Delta})$ BDNF, $100 \mathrm{pg} / \mathrm{ml}$; (ם) L-NAME, $1 \mathrm{mM}$; $(\bigcirc)$ trophic factor deprivation. Values are the mean \pm SD of three independent experiments performed in duplicate.

Table 1. L-Arginine reverses the protective effects of NOS inhibition

\begin{tabular}{lcr} 
Treatment & $\begin{array}{c}\text { Motor neuron } \\
\text { survival }^{*}(\%)\end{array}$ & $n$ \\
\hline None & $35 \pm 4$ & 8 \\
BDNF & $100 \pm 4$ & 8 \\
L-NAME & $80 \pm 6$ & 4 \\
L-NAME + L-arginine & $47 \pm 3$ & 4 \\
L-NAME + D-arginine & $79 \pm 4$ & 4 \\
D-NAME & $32 \pm 6$ & 4 \\
\hline
\end{tabular}

*The percentage of motor neuron survival was determined $24 \mathrm{hr}$ after plating, as indicated in Materials and Methods. The number of cells in BDNF-treated cultures at $24 \mathrm{hr}$ was taken as $100 \%$. Values are the mean $\pm \mathrm{SD}$ of $n$ determinations from at least two independent experiments. The concentrations were $100 \mathrm{pg} / \mathrm{ml} \mathrm{BDNF}, 1$ mM L-NAME; 2 mM L-arginine; 2 mм D-arginine; and 1 mм D-NAME.

\section{Table 2. Effects of NO on motor neuron survival}

\begin{tabular}{lcr} 
Treatment & $\begin{array}{c}\text { Motor neuron } \\
\text { survival* }(\%)\end{array}$ & $n$ \\
\hline None & $35 \pm 4$ & 10 \\
BDNF & $100 \pm 4$ & 10 \\
BDNF + DETA-NONOate & $102 \pm 7$ & 6 \\
DETA-NONOate & $31 \pm 4$ & 4 \\
DETA & $35 \pm 5$ & 4 \\
L-NAME + DETA & $79 \pm 8$ & 4 \\
L-NAME + DETA-NONOate & $50 \pm 6$ & 6 \\
L-NAME + DETA-NONOate + SOD & $27 \pm 4$ & 4 \\
SOD & $37 \pm 8$ & 4
\end{tabular}

*The percentage of motor neuron survival was determined $24 \mathrm{hr}$ after plating, as described in Materials and Methods. The number of cells in BDNF-treated cultures at $24 \mathrm{hr}$ was taken as $100 \%$. Values are mean $\pm \mathrm{SD}$ of $n$ determination from at least two independent experiments. The concentrations were $100 \mathrm{pg} / \mathrm{ml} \mathrm{BDNF}, 20 \mu \mathrm{M}$ DETA-NONOate; $20 \mu \mathrm{M}$ DETA; $1 \mathrm{~mm}$ L-NAME; and $1000 \mathrm{U} / \mathrm{ml}$ SOD. Similar results were obtained by using up to $25,000 \mathrm{U} / \mathrm{ml} \mathrm{SOD}$.

ation of NO by DETA-NONOate partially restored nitrotyrosine immunoreactivity in L-NAME-treated motor neurons (Fig. 10). Staining with nitrotyrosine antibodies was blocked completely by alanyl-3-nitrotyrosyl-glycine or 3-nitrotyrosine, but it was not affected by tyrosine at the same concentration. 


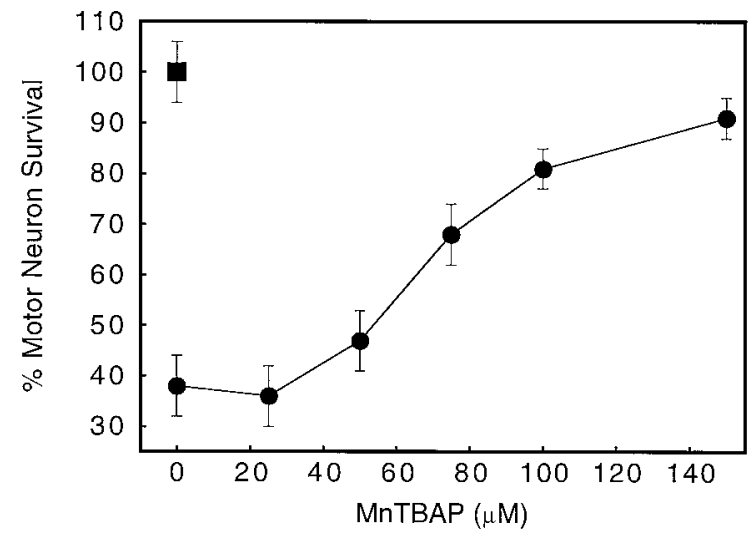

Figure 7. Intracellular superoxide scavengers prevent motor neuron death induced by trophic factor deprivation. Cultures were exposed to the indicated concentrations of the SOD mimetic manganese TBAP (•) immediately after plating. Motor neuron survival was determined as described in Materials and Methods $24 \mathrm{hr}$ after plating. (ם) BDNF, 100 $\mathrm{pg} / \mathrm{ml}$. Values are the mean $\pm \mathrm{SD}$ of two independent experiments performed in duplicate.

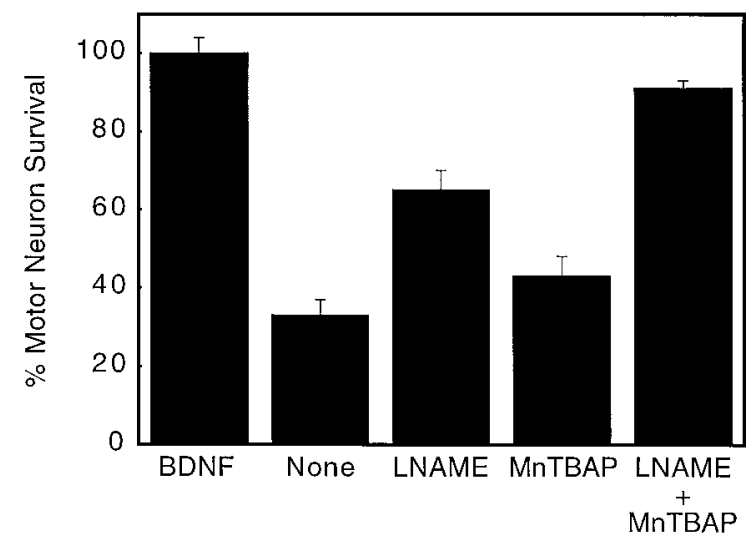

Figure 8. Manganese TBAP potentiates the protective effect of L-NAME on motor neuron survival. Motor neurons were exposed to L-NAME $(10 \mu \mathrm{M})$, manganese TBAP $(50 \mu \mathrm{M})$, or both simultaneously. Cell survival was determined as described in Materials and Methods $24 \mathrm{hr}$ after treatment. Values are the mean \pm SD of three independent experiments performed in duplicate.

\section{DISCUSSION}

Motor neuron apoptosis induced by trophic factor deprivation in vitro involved both increased NO production after the induction of neuronal NOS and augmented intracellular production of superoxide. Prevention of neuronal NOS expression by BDNF or inhibition of NO production as well as increased intracellular superoxide scavenging prevents motor neuron death and the increase in nitrotyrosine immunoreactivity (Fig. 10). These results suggest that motor neuron apoptosis was initiated by the endogenous formation of peroxynitrite from the reaction of NO with superoxide.

Loss of trophic support is well known to cause neuronal death in vitro and in animal models of motor neuron degeneration. Several lines of evidence suggest that the production of NO is involved in motor neuron death in vivo. Avulsion of ventral root in rat spinal neurons leads to a rapid induction of $\mathrm{NOS}(\mathrm{Wu}$, 1993), and chronic treatment with the NOS inhibitor nitro-Larginine prevents motor neuron death (Wu and $\mathrm{Li}, 1993)$. Continuous infusion of BDNF after ventral root avulsion is reported to inhibit induction of NOS and cell death (Novikov et al., 1995). Distal axonal injury generally does not induce motor neuron degeneration, suggesting that Schwann cell-derived trophic support is sufficient to prevent the induction of neuronal NOS and motor neuron death. In addition to disrupting target- and Schwann cell-derived trophic support, ventral root avulsion can alter motor neuron activity (Greensmith and Vrbová, 1996) and disrupt spinal blood vessels, which are closely associated with the ventral root. Elucidation of the interdependent roles among trophic factor deprivation, NO production, and motor neuron death is nearly impossible to accomplish in vivo.

In the present study we found that purified embryonic motor neurons deprived of BDNF rapidly induced neuronal NOS, and the resulting production of NO contributed to the subsequent death by an apoptotic mechanism. Because motor neurons are maintained in a low-density culture $\left(200\right.$ cells $\left.\cdot \mathrm{cm}^{-2}\right)$, endogenous NO was acting predominantly on the same cell from which it was produced. Inhibition of NO synthesis protected the motor neurons from cell death, and the protection was reversed by a physiologically relevant extracellular steady-state concentration of NO $(<100 \mathrm{~nm})$. The same rate of NO production was not toxic to BDNF-treated motor neurons and did not potentiate cell death of BDNF-deprived motor neurons (Table 1), showing that NO itself was neither sufficient nor limiting to induce motor neuron apoptosis. Analogs of cGMP are protective for motor neurons (A. G. Estévez, unpublished observations); thus stimulation of soluble guanylate cyclase is unlikely to be responsible for the apoptosis induced by NO.

Our data suggest that the formation of peroxynitrite could account for NO-dependent cell death. In agreement with this hypothesis, trophic factor-deprived motor neurons were substantially more immunoreactive for nitrotyrosine. Although peroxynitrite may induce apoptosis by actions unrelated to tyrosine nitration, nitration is an excellent marker to show formation of peroxynitrite. NO itself does not produce nitrotyrosine, which implies that it had been transformed into a more powerful oxidant (Beckman et al., 1994; Beckman, 1996b). Manganese TBAP, a membrane-permeant SOD mimetic (Faulkner et al., 1994), protected motor neurons from apoptosis and reduced tyrosine nitration, supporting a role for intracellular superoxide reacting with NO to initiate apoptosis. Downregulation of SOD by using antisense oligonucleotides has been shown to stimulate apoptosis in PC12 cells (Troy and Shelanski, 1994; Troy et al., 1996) and motor neurons (Rothstein et al., 1994). Potentiation of the protection of low concentrations of L-NAME by manganese TBAP strongly supports a role for peroxynitrite in the induction of motor neuron apoptosis by trophic factor deprivation.

Extracellular SOD was not protective to BDNF-deprived motor neurons. This is consistent with the results of Saez et al. (1987) in ganglion cell cultures, who showed that SOD was protective to neurons only when it was delivered intracellularly. The addition of SOD increased the toxicity of NO generated from DETA-NONOate to BDNF-deprived neurons exposed to L-NAME. The superoxide flux generated by autoxidation of the culture media substantially lowered the steady-state concentration of NO. Although peroxynitrite was generated extracellularly, the vast majority of this peroxynitrite reacts with serum components before reaching a motor neuron. In the presence of extracellular SOD, the greater concentration of extracellular NO also increases the intracellular concentration of NO, which competes more effectively for intracellular superoxide and therefore produces more peroxynitrite within the motor neuron. 

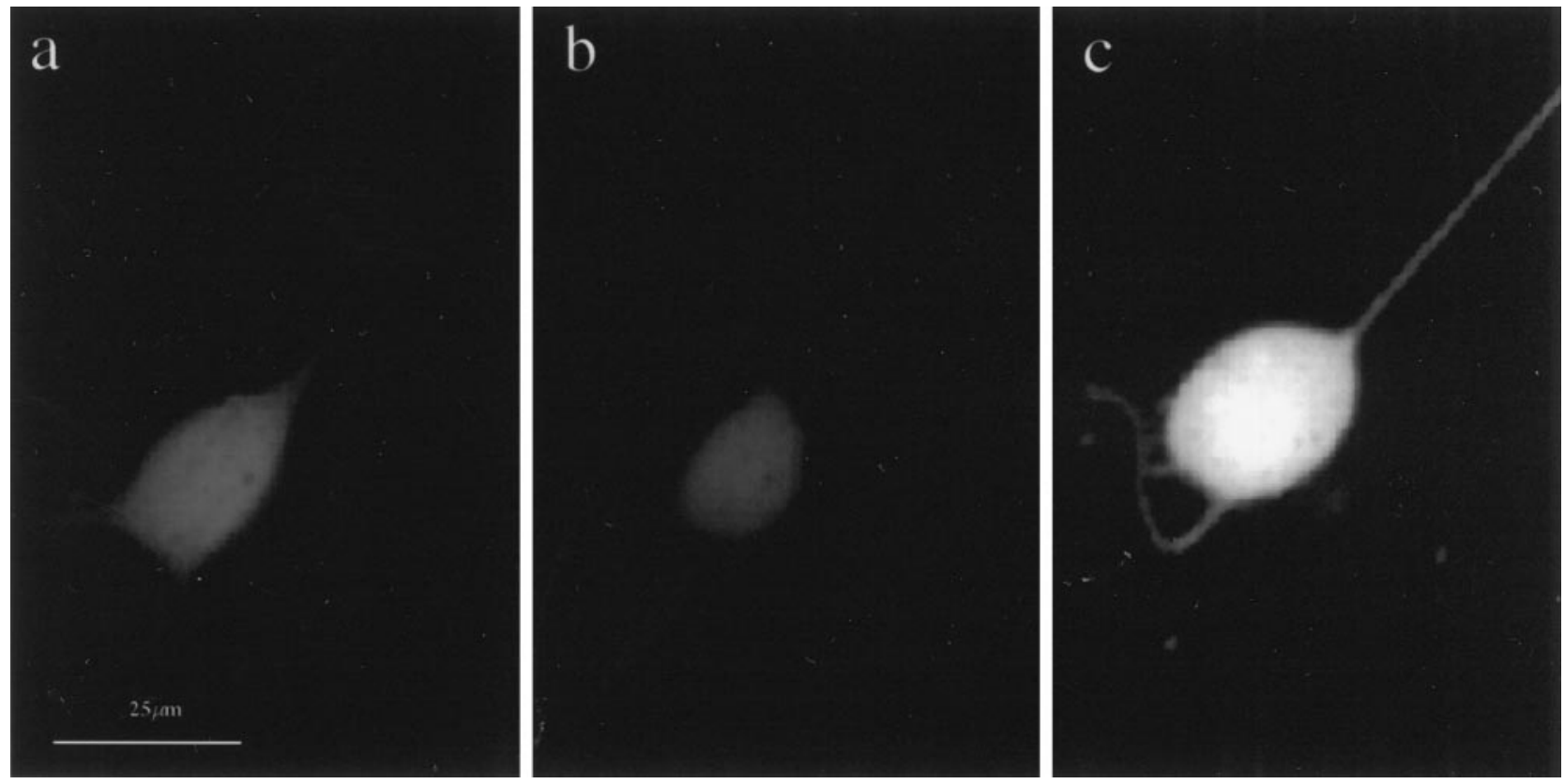

Figure 9. Nitrotyrosine immunoreactivity in cultured motor neurons. Shown are immunofluorescence images of motor neurons stained for nitrotyrosine $24 \mathrm{hr}$ after plating in the presence of $100 \mathrm{pg} / \mathrm{ml} \mathrm{BDNF}(a), 1 \mathrm{~mm} \mathrm{~L}-\mathrm{NAME}$ without BDNF $(b)$, or in the absence of supplements $(c)$. Scale bar, $25 \mu \mathrm{m}$.

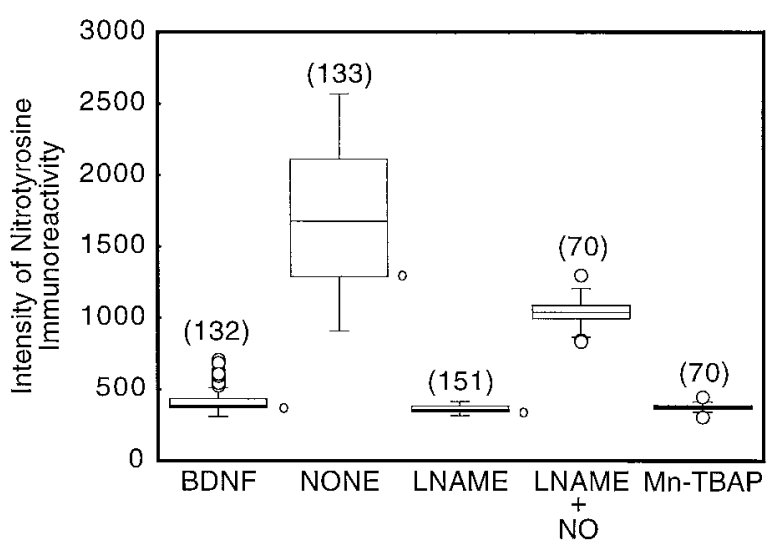

Figure 10. Quantification of the intensity of nitrotyrosine immunofluorescence. Motor neurons were cultured in the presence of BDNF (100 $\mathrm{pg} / \mathrm{ml})$, L-NAME $(1 \mathrm{mM})$, or without supplements. Cultures were fixed and processed for immunofluorescence $24 \mathrm{hr}$ after plating, as indicated in Materials and Methods. The number of cells quantified in each group is given in parentheses. Individual cells were chosen randomly under phasecontrast microscopy before quantifying fluorescence. Data are shown as a box and whiskers plot (Tukey, 1977). The central line gives the median, and the boxes contain the upper to lower quartiles, thereby encompassing $50 \%$ of the data. The whiskers show the maximum and minimum for each data set. When individual data lie outside the median \pm 1.5 times the difference between the upper and lower quartiles, they are drawn as separate circles. Ovals at the right side of boxes are the individual values of the cells shown in Figure 9 when they are digitized.

Approximately 50 missense mutations in $\mathrm{Cu} / \mathrm{Zn}$ SOD have been associated with a subpopulation of familial ALS patients (Siddique and Hentati, 1996; Cudkowicz et al., 1997), although the mechanisms by which these mutations cause the selective degeneration of motor neurons remain unknown. Recently, the expression of a dominant-negative inhibitor of ICE in transgenic mice carrying the ALS mutant SOD G93A has been shown to slow the progression of the disease (Friedlander et al., 1997).
Furthermore, overexpression of bcl-2 delays the onset of symptoms in the G93A mice (Kostic et al., 1997). These results suggest that the ALS SOD mutants induce apoptosis in adult motor neurons in transgenic mice.

Because all but one of the mutations are dominant in action and because transgenic mice expressing the mutant forms of SOD develop motor neuron disease, a gain-of-function generally is considered to be more likely than a loss of superoxide scavenging activity (Gurney et al., 1994). We have suggested that the gainof-function by mutant SODs may result from increased efficiency of catalyzing tyrosine nitration by peroxynitrite (Beckman et al., 1993). Recent evidence indicates that nitrotyrosine is increased in upper and lower motor neurons of ALS (Abe et al., 1995; Chou et al., 1996a,b). Bruijn et al. (1997) have shown that the amino acid nitrotyrosine accumulates in transgenic mice bearing the G37R SOD mutation at the time when the disease develops but could not demonstrate an increase in nitrated proteins by Western blotting in ALS mice. The presence of nitrotyrosine suggests that peroxynitrite has been produced in motor neurons of ALS patients and in transgenic mice. Our results show that the endogenous formation of peroxynitrite after the induction of neuronal NOS is sufficient to induce apoptosis in embryonic motor neurons. Understanding how peroxynitrite induces apoptosis in cultured embryonic motor neurons may help to elucidate how mutations to SOD cause the death of adult motor neurons in ALS.

\section{REFERENCES}

Abe K, Pan L-H, Watanabe M, Kato T, Itoyama Y (1995) Induction of nitrotyrosine-like immunoreactivity in the lower motor neuron of amyotrophic lateral sclerosis. Neurosci Lett 199:152-154.

Arakawa Y, Sendtner M, Thoenen H (1990) Survival effect of ciliary neurotrophic factor (CNTF) on chick embryonic motoneurons in culture: comparison with other neurotrophic factors and cytokines. J Neurosci 10:3507-3515.

Beckman JS (1996a) The physiological and pathological chemistry of nitric oxide. In: Nitric oxide: principles and actions (Lancaster JR, ed), pp 1-82. New York: Academic.

Beckman JS (1996b) Oxidative damage and tyrosine nitration from peroxynitrite. Chem Res Toxicol 9:836-844. 
Beckman JS, Conger K (1995) Direct measurement of nitric oxide in solutions with an ozone-based chemiluminescent detector. Methods 7:35-39.

Beckman JS, Carson M, Smith CD, Koppenol WH (1993) ALS, SOD, and peroxynitrite. Nature 364:584.

Beckman JS, Ye YZ, Anderson P, Chen J, Accavetti MA, Tarpey MM, White CR (1994) Extensive nitration of protein tyrosines in human atherosclerosis detected by immunohistochemistry. Biol Chem Hoppe Seyler 375:81-88.

Beckman JS, Ye YZ, Chen J, Conger K (1996) The interactions of nitric oxide with oxygen radicals and scavengers in cerebral ischemic injury. In: Advances in neurology 71: cellular and molecular mechanisms of ischemic brain damage (Siesjö BK, Wieloch T, eds), pp 339-354. Philadelphia: Lippincott-Raven.

Bonfoco E, Krainc D, Ankarcrona M, Nicotera P, Lipton SA (1995) Apoptosis and necrosis: two distinct events induced, respectively, by mild and intense insults with $N$-methyl-D-aspartate or nitric oxide/ superoxide in cortical cell cultures. Proc Natl Acad Sci USA 92:7162-7166.

Bruijn LI, Beal MF, Becher MW, Schulz JB, Wong PC, Price DL, Cleveland DW (1997) Elevated free nitrotyrosine levels, but not protein-bound nitrotyrosine or hydroxyl radicals, throughout amyotrophic lateral sclerosis (ALS)-like disease implicate tyrosine nitration as an aberrant in vivo property of one famillial ALS-linked superoxide dismutase 1 mutant. Proc Natl Acad Sci USA 94:7606-7611.

Chandler CE, Parsons LM, Hosang M, Shooter EM (1984) A monoclonal antibody modulates the interaction of nerve growth factor with PC12 cells. J Biol Chem 259:6882-6889.

Chou SM, Wang HS, Komai K (1996a) Colocalization of NOS and SOD1 in neurofilament accumulation within motor neurons of amyotrophic lateral sclerosis: an immunohistochemical study. J Chem Neuroanat 10:249-258.

Chou SM, Wang HS, Taniguchi A (1996b) Role of SOD-1 and nitric oxide/cyclic GMP cascade on neurofilament aggregation in ALS/ MND. J Neurol Sci [Suppl] 139:16-26.

Coyle JT, Puttfarcken P (1993) Oxidative stress, glutamate, and neurodegenerative disorders. Science 262:689-695.

Cudkowicz ME, McKenna-Yasek D, Sapp PE, Chin W, Geller HR, Brown RH (1997) Epidemiology of mutations in superoxide dismutase in amyotrophic lateral sclerosis. Ann Neurol 41:210-221.

Culcasi M, Lafon-Cazal M, Pietri S, Bockaert J (1994) Glutamate receptors induce a burst of superoxide via activation of nitric oxide synthase in arginine-depleted neurons. J Biol Chem 269:12589-12593.

Dawson VL, Dawson TM, London ED, Bredt DS, Snyder SH (1991) Nitric oxide mediates glutamate neurotoxicity in primary cortical cultures. Proc Natl Acad Sci USA 88:6368-6371.

Dawson VL, Kizushi VM, Huang KL, Snyder SH, Dawson TM (1996) Resistance to neurotoxicity in cortical cultures from neuronal nitric oxide synthase-deficient mice. J Neurosci 16:2479-2487.

Ericson J, Thor S, Edlund T, Jessell T, Yamada T (1992) Early stages of motor neuron differentiation revealed by expression of homeobox gene Islet-1. Science 256:1555-1560.

Estévez AG, Radi F, Barbeito L, Shin JT, Thompson JA, Beckman JS (1995) Peroxynitrite-induced cytotoxicity in PC12 cells: evidence for an apoptotic mechanism differentially modulated by neurotrophic factors. J Neurochem 65:1543-1550.

Faulkner KM, Liochev SI, Fridovich I (1994) Stable Mn(III) porphyrins mimic superoxide dismutase in vitro and substitute for it in vivo. J Biol Chem 269:23471-23476.

Friedlander RM, Brown RH, Gagliardini V, Wang J, Yuan J (1997) Inhibition of ICE slows ALS in mice. Nature 388:31.

Good PF, Werner P, Hsu A, Olanow CW, Perl DP (1996) Evidence for neuronal oxidative damage in Alzheimer's disease. Am J Pathol 149:21-28.

Gouin A, Bloch-Gallego E, Tanaka H, Rosenthal A, Henderson CE (1996) Transforming growth factor-beta 3, glial cell line-derived neurotrophic factor, and fibroblast growth factor- 2 act in different manners to promote motoneuron survival in vitro. J Neurosci Res 43:545-464.

Greensmith L, Vrbová G (1996) Motoneurone survival: a functional approach. Trends Neurosci 19:450-455.

Gurney ME, Pu H, Chiu AY, Dal Corto MC, Polchow CY, Alexander DD, Caliendo J, Hentati A, Kwon YW, Deng H-X, Chen W, Zhai P, Sufit RL, Siddique T (1994) Motor neuron degeneration in mice that express a human $\mathrm{Cu}, \mathrm{Zn}$ superoxide dismutase mutation. Science 264:1772-1775.
Hantraye P, Brouillet E, Ferrante R, Palfi S, Bolan R, Matthews RT, Beal MF (1996) Inhibition of neuronal nitric oxide synthase prevents MPTP-induced parkinsonism in baboons. Nat Med 2:1017-1021.

Henderson CE, Camu W, Mettling C, Gouin A, Poulsen K, Karihaloo M, Rullamas J, Evans T, McMahon SB, Armanini MP, Berkemeier L, Phillips HS, Rosenthal A (1993) Neurotrophins promote motor neuron survival and are present in embryonic limb bud. Nature 363:266-270.

Henderson CE, Phillips HS, Pollock RA, Davies AM, Lemeulle C, Armanini M, Simpson LC, Moffet B, Vandlen RA, Koliatsos VE, Rosenthal A (1994) GDNF: a potent survival factor for motoneurons present in peripheral nerve and muscle. Science 266:1062-1064.

Henderson CE, Bloch-Gallego E, Camu W (1995) Purification and culture of embryonic motor neurons. In: Neuronal cell culture: a practical approach (Cohen J, Wilkin G, eds), pp 69-81. Oxford, UK: IRL.

Herdegen T, Brecht S, Mayer B, Leah J, Kummer W, Bravo R, Zimmermann M (1993) Long-lasting expression of JUN and KROX transcription factors and nitric oxide synthase in intrinsic neurons of the rat brain following axotomy. J Neurosci 13:4130-4145.

Herdegen T, Rudiger S, Mayer M, Bravo R, Zimmermann M (1994) Expression of nitric oxide synthase and colocalisation with Jun, Fos, and Krox transcription factors in spinal cord neurons following noxious stimulation of the rat hindpaw. Mol Brain Res 22:245-258.

Hrabie JA, Klose JR, Wink DA, Keefer LK (1993) New nitric oxidereleasing zwitterions derived from polyamines. J Org Chem 58:1472-1476.

Huang Z, Huang PL, Panahian N, Dalkara T, Fishman MC, Moskowitz MA (1994) Effects of cerebral ischemia in mice deficient in neuronal nitric oxide synthase. Science 265:1883-1885.

Hughes RA, Sendtner M, Thoenen H (1993) Members of several gene families influence survival of rat motoneurons in vitro and in vivo. J Neurosci Res 36:663-671.

Ischiropoulos H, Zhu L, Chen J, Tsai HM, Martin JC, Smith CD, Beckman JS (1992) Peroxynitrite-mediated tyrosine nitration catalyzed by superoxide dismutase. Arch Biochem Biophys 298:431-437.

Kostic V, Jackson-Lewis V, de Bilbao F, Dubois-Dauphin M, Przedborski S (1997) Bcl-2: prolonging life in a transgenic mouse model of familial amyotrophic lateral sclerosis. Science 277:559-562.

Lafon-Cazal M, Pietri S, Culcasi M, Bockaert J (1993a) NMDAdependent superoxide production and neurotoxicity. Nature 364:535-537.

Lafon-Cazal M, Culcasi M, Gaven F, Pietri S, Bockaert J (1993b) Nitric oxide, superoxide, and peroxynitrite: putative mediator of NMDAinduced cell death in cerebellar granule cells. Neuropharmacology 32:1259-1266.

Li L, Wu W, Lin L-FH, Lei M, Oppenheim RW, Houenou LJ (1995) Rescue of adult mouse motoneurons from injury-induced cell death by glial cell line-derived neurotrophic factor. Proc Natl Acad Sci USA 92:9771-9775.

Meyer W, Neurand K, Bartels T, Kojda G, Mayer B (1994) Demonstration of NADPH-diaphorase (NO-synthase) in the apocrine and eccrine skin glands of domesticated mammals. Cell Mol Biol 40:175-181.

Milligan CE, Prevette D, Yaginuma H, Homma S, Cardwell C, Fritz LC, Tomasselli KJ, Oppenheim RW, Schwartz M (1995) Peptide inhibitors of the ICE protease family arrest programmed cell death of motoneurons in vivo and in vitro. Neuron 15:385-393.

Neff NT, Prevette D, Houenou LJ, Lewis ME, Glicksman A, Yin Q-W, Oppenheim RW (1993) Insulin-like growth factors: putative musclederived trophic agents that promote motoneuron survival. J Neurobiol 24:1578-1588.

Novikov L, Novikova L, Kellerth J-O (1995) Brain-derived neurotrophic factor promotes survival and blocks nitric oxide synthase expression in adult rat spinal motoneurons after ventral root avulsion. Neurosci Lett 200:45-48.

Oppenheim RW, Qin-Wei Y, Prevette D, Yan Q (1992) Brain-derived neurotrophic factor rescues developing avian motoneurons from cell death. Nature 360:755-757.

Oppenheim RW, Houenou LJ, Johnson JE, Lin L-FH, Li L, Lo AC, Newsome AL, Prevette DM, Wang S (1995) Developing motor neurons rescued from programmed cell death by GDNF. Nature 373:344-346.

Pennica D, Arce V, Swanson TA, Vejsada R, Pollock RA, Armanini M, Dudley K, Phillips HS, Rosenthal A, Kato AC, Henderson CE (1996) Cardiotrophin-1, a cytokine present in embryonic muscle, supports long-term survival of spinal motoneurons. Neuron 17:63-74. 
Przedborski S, Donaldson D, Jakowec M, Kish SJ, Guttman M, Rosoklija G, Hays AP (1996) Brain superoxide dismutase, catalase, and glutathione peroxidase activities in amyotrophic lateral sclerosis. Ann Neurol 39:158-165.

Rothstein JD, Bristol LA, Hosler B, Brown Jr RH, Kuncl RW (1994) Chronic inhibition of superoxide dismutase produces apoptotic death of spinal neurons. Proc Natl Acad Sci USA 91:4155-4159.

Saez JS, Kessler JA, Bennett MVL, Spray DC (1987) Superoxide dismutase protects cultured neurons against death by starvation. Proc Natl Acad Sci USA 84:3056-3059.

Schmalbruch H, Rosenthal A (1995) Neurotrophin-4/5 postpones the death of injured motoneurons in newborn rats. Brain Res 700:254-260.

Schulz JB, Huang PL, Matthews RT, Passov D, Fishman MC, Beal MF (1996) Striatal malonate lesions are attenuated in neuronal nitric oxide synthase knockout mice. J Neurochem 67:430-433.

Sendtner M, Holtmann B, Kolbeck R, Thoenen H, Barde Y-A (1992) Brain-derived neurotrophic factor prevents the death of motoneurons in newborn rats after nerve section. Nature 360:757-759.

Shaul PW, North AJ, Snyder SH, Star RA (1995) Prolonged in vivo hypoxia enhances nitric oxide synthase type I and type III gene expression in adult rat lung. Am J Respir Cell Mol Biol 13:167-174.

Siddique T, Hentati A (1996) Familial amyotrophic lateral sclerosis. Clin Neurosci 3:338-347.

Smith MA, Harris PL, Sayre LM, Beckman JS, Perry G (1997) Widespread peroxynitrite-mediated damage in Alzheimer disease. J Neurosci 17:2653-2657.

Spear N, Estévez AG, Barbeito L, Beckman JS, Johnson GVW (1997) Nerve growth factor protects PC12 cells against peroxynitrite-induced apoptosis via a mechanism dependent on phosphatidylinositol-3 kinase. J Neurochem 69:53-59.

Szabo C, Day BJ, Salzman AL (1996) Evaluation of the relative contri- bution of nitric oxide and peroxynitrite to the suppression of mitochondrial respiration in immunostimulated macrophages using a manganese mesoporphyrin superoxide dismutase mimetic and peroxynitrite scavenger. FEBS Lett 381:82-86.

Troy CM, Shelanski ML (1994) Down-regulation of copper/zinc superoxide dismutase causes apoptotic death in PC12 neuronal cells. Proc Natl Acad Sci USA 91:6384-6387.

Troy CM, Derossi D, Prochiantz A, Greene LA, Shelanski ML (1996) Downregulation of $\mathrm{Cu} / \mathrm{Zn}$ superoxide dismutase leads to cell death via the nitric oxide-peroxynitrite pathway. J Neurosci 16:253-261.

Tsuchida T, Ensini M, Morton SB, Baldassare M, Edlund T, Jessell TM, Pfaff SL (1994) Topographic organization of embryonic motor neurons defined by expression of LIM homeobox genes. Cell 79:957-970.

Tukey JW (1977) Exploratory data analysis. Reading, MA: Addison-Wesley.

Wu W (1993) Expression of nitric-oxide synthase (NOS) in injured CNS neurons as shown by NADPH diaphorase histochemistry. Exp Neurol 120:153-159.

Wu W, Li L (1993) Inhibition of nitric oxide synthase reduces motoneuron death due to spinal root avulsion. Neurosci Lett 153:121-124.

Yan Q, Johnson Jr EM (1988) An immunohistochemical study of the nerve growth factor receptor in developing rats. J Neurosci 8:3481-3498.

Yan Q, Elliot J, Snider WD (1992) Brain-derived neurotrophic factor rescues spinal motor neurons from axotomy-induced cell death. Nature 360:753-755.

Yan Q, Elliot JL, Matheson C, Sun J, Zhang L, Mu X, Rex KL, Snider WD (1993) Influences of neurotrophins on mammalian motoneurons in vivo. J Neurobiol 24:1555-1577.

Ye YZ, Strong M, Huang Z-Q, Beckman JS (1996) Antibodies that recognize nitrotyrosine. Methods Enzymol 269:201-209. 